\title{
SiM
}

\section{Hindrances and Successes: Mapping the 2006 East Amarillo Complex Wildfires in Gray County, Texas}

\author{
By Renaldo J. Arroyo and Tina Delahunty
}

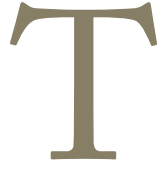

he East Amarillo Complex wildfires were the largest wildfire event in the United States in 2006 with over 367,000 ha burned. ${ }^{1}$ Indeed the National Interagency Fire Center data places the event as the largest in the contiguous 48 states since the Yellowstone fires of $1988 .{ }^{1}$ The complex was composed of two large wildfires: the Borger Fire, the more northerly, and the I-40 Fire, the more southerly. It affected nine counties in the Texas Panhandle even though it only burned for a few days. The conditions that supported the fires of this complex were the perfect storm for extreme grassland fire (low humidity, high velocity winds and high air temperature, and the nature of the fuels). ${ }^{2}$ It was these conditions that fostered 11-foot flames and promoted the fires to spread 45 miles in just 9 hours. ${ }^{2}$ These fires resulted in the largest loss of human life by wildfire in $2006 .^{2}$

\section{Gray County, Texas}

The Texas Panhandle is the northwestern region of Texas located within the southern Great Plains of the United States. Gray County is centrally located in the Panhandle and is home to southern shortgrass prairie. This prairie type contains sandy soils dominated by species such as little bluestem (Schizachyrium scoparium), sand shinnery oak (Quercus havardii), and sand sagebrush (Artemisia filifolia). ${ }^{3}$ Prairie grasslands such as these experience frequent fire with a short fire return interval of 5 to 10 years. ${ }^{3}$ In drought years, common on the Plains, large-scale prairie fires occur due to abundant and continuous fuel, especially when following 1 to 3 years of above average precipitation. ${ }^{3}$ During times of low relative humidity, high winds, and high air temperatures, these fires can affect large areas and travel long distances. ${ }^{3}$ Large-scale wildfire is not uncommon in this region of Texas. ${ }^{3,4}$

Gray County was the only county in the Panhandle affected by both fires of the East Amarillo Complex. Pampa, the largest city in the county, is 60 miles northeast of Amarillo, Texas. The county has a relatively small population, a little over 22,500, but is sizeable at 240,351 ha. ${ }^{5}$ The county lies on the eastern edge of the high plains and includes the ecological transition to rolling plains. There are two predominant environments: the flat plains in the north and west and the Red River breaks that transition to the rolling plains in the east and south ${ }^{6}$ (Fig. 1). The northwest was burned by the Borger Fire and the Red River breaks were burned by the I-40 Fire.

\section{Burned Area Mapping and Remote Sensing}

In this article, we document the use of remotely sensed data (defined as digital information gathered from a sensing and recording device on an air or spacecraft) in fire effects assessment, using minimal technical vocabulary for those interested in using aerial and satellite imagery, but not particularly savvy about the mathematical algorithms behind the analysis. We then provide an example of the use of remote sensing to map the burn area of the 2006 East Amarillo Complex wildfires in Gray County. The example illustrates the hindrances and successes of the project, providing insight to anyone interested in landscape-level burned area mapping and those considering dabbling in the use of remotely sensed imagery.

\section{The Use of Remotely Sensed Data in Fire Effects Assessment}

The era of digital aerial and satellite imagery has enhanced the ability of land managers and ecologists to perform landscape-level studies in a more cost-effective and timely manner. Using remotely sensed digital imagery enables spatial models "to expand from local to regional applications," in remedying the inaccessible nature of many wildfires, and provides researchers with a "means to quantify patterns of variation in space and time." ${ }^{8}$ Chuvieco and Kasischke, reporting on the results of an international workshop in 2005, reviewed the uses of remotely sensed data in fire science and fire management and established three important areas of research: burned area mapping, environmental dynamics postfire, and modeling for fire risk.

Available literature on the use of remotely sensed data and associated technologies in the spatial/environmental analysis of fire and fire risk exists for a wide range of ecotypes in many countries, including Australia, Botswana, Brazil, Canada, Central African Republic, Greece, Italy, Kalimantan, Spain, Sumatra, Turkey, the United States, and Russia (see Further Readings online at http://dx.doi.org/ 


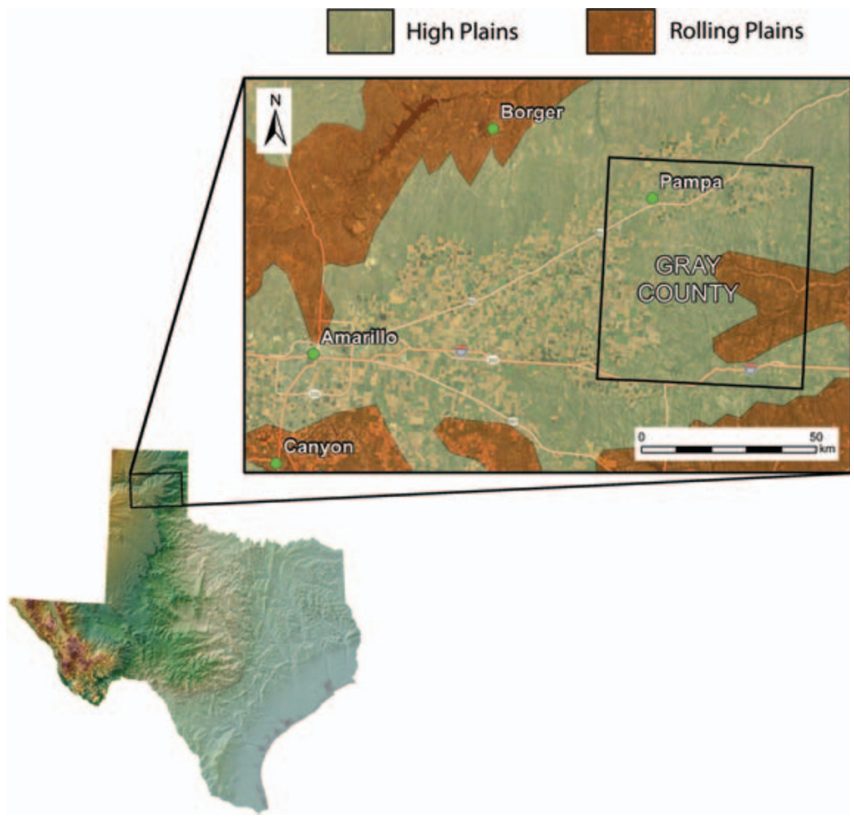

Figure 1. Elevation ranges of Texas. Subset of central Panhandle with natural regions from Amarillo to eastern Gray County, Texas.

10.2111/RANGELANDS-D-11-00052.s1 for the citations of these studies). These projects utilize a range of remotely sensed imagery from various sensors on board satellites circumnavigating the Earth. Images can vary from coarse spatial resolution (meaning a relatively large area of land is represented by each pixel of the imagery) of $10-\mathrm{km}$ to $250-1,000-\mathrm{m}$ resolution, to moderate resolution of $28.5-$ $60-\mathrm{m}$ resolution, to fine resolution of $1-4-\mathrm{m}$ resolution. Combinations of two or more types of imagery are also used. Another aspect of digital imagery related to spatial resolution is file size. For example, a fine-resolution image covering $100 \mathrm{~km}^{2}$ has a much larger file size than a coarseresolution image of the same area. A third aspect of digital imagery obtained via satellite sensors is spectral resolution characteristics, which refers to the character of the ground reflectance captured. Some sensors capture reflectance of visible wavelengths, some capture infrared, etc. Most air- and space-borne sensors capture multiple bands of electromagnetic reflectance so the type of research at hand dictates which type of imagery is best. For example, infrared reflectance is useful for identifying pixels that represent vegetation. When multiple bands of electromagnetic reflectance are captured, each pixel, as a ground location, contains reflectance information for each band. Its unique combination of reflectance values is representative of its associated land cover. This is called the pixel's spectral signature and aids in classifying imagery into generalized land cover types. Essentially, classification is where thousands of possible combinations of landscape reflection values of pixels are combined into fewer land cover classes. Various algorithms are used for this process, the primary being maximum likelihood. For example, an original image may reveal pine forest, scrub, grassland, etc. Classification, led by the analyst, could place these into one category-vegetation. This classification can be carried out on multiple images of different dates enabling percent-change analysis through time.

\section{The Appeal of Landsat Imagery}

Cohen and Goward note that "At the core of developments in remote sensing has been the Landsat program." "Landsat" refers to a particular series of satellites, the first of which, Landsat 1, began orbiting the Earth in $1972 .{ }^{7}$ Landsat 5 and Landsat 7 are operating today and each has a revisit time of 16 days (they capture an image of the same spot on Earth every 16 days). Landsat Thematic Mapper (TM) refers to a type of sensor employed on Landsat 5 (from 1984) that captures $28.5-\mathrm{m}-$ or $30-\mathrm{m}$-resolution imagery of land cover information in individual reflectance layers of blue, green, red, near infrared, two bands of midinfrared, and one thermal (at $120-\mathrm{m}$ resolution). Landsat 7's sensor captures Enhanced Thematic Mapper Plus (ETM+) images with an additional panchromatic band at $15-\mathrm{m}$ resolution (the thermal layer resolution is at $60 \mathrm{~m}$ ). This overall moderate resolution, and associated moderate file size, is known to be appropriate for obtaining information about land cover at the landscape level. ${ }^{10}$ Also contributing to its appeal is its availability. In 2009, the US Geological Survey (USGS) opened the entire Landsat archive to the public via the internet-based, free, Earth Resources Observation and Science Center's USGS Global Visualization Viewer (GloVis).' More than 50\% of the studies referenced in Further Readings utilized Landsat TM or ETM+ imagery for various purposes, such as measuring effects of prescribed burning on wildfires, predicting fire activity and vulnerability, assessing fire and burn severity and postfire vegetation diversity and density, and mapping burned areas (see Further Readings online for the citations of these studies).

\section{Mapping the East Amarillo Complex Fires in Gray County, Texas}

Our initial goal was to utilize Landsat imagery to generate burned-area quantitative data and create a burned-area map for Gray County, Texas, after the wildfires of 2006. Two images were required: a preceding-fire image for determining landscape variability before the 12 March start date of the fires and a postfire image as close as possible to the contain/control date of 18 March.

Obtaining the imagery. Limitation of the satellite sensor technology is one of the biggest problems with using remotely sensed data in fire-related research. ${ }^{9}$ Though GloVis had many images available for the time frame of interest, it became obvious that there were quality issues with much of the imagery being perused. After some

For more on GloVis, see http://glovis.usgs.gov/. 


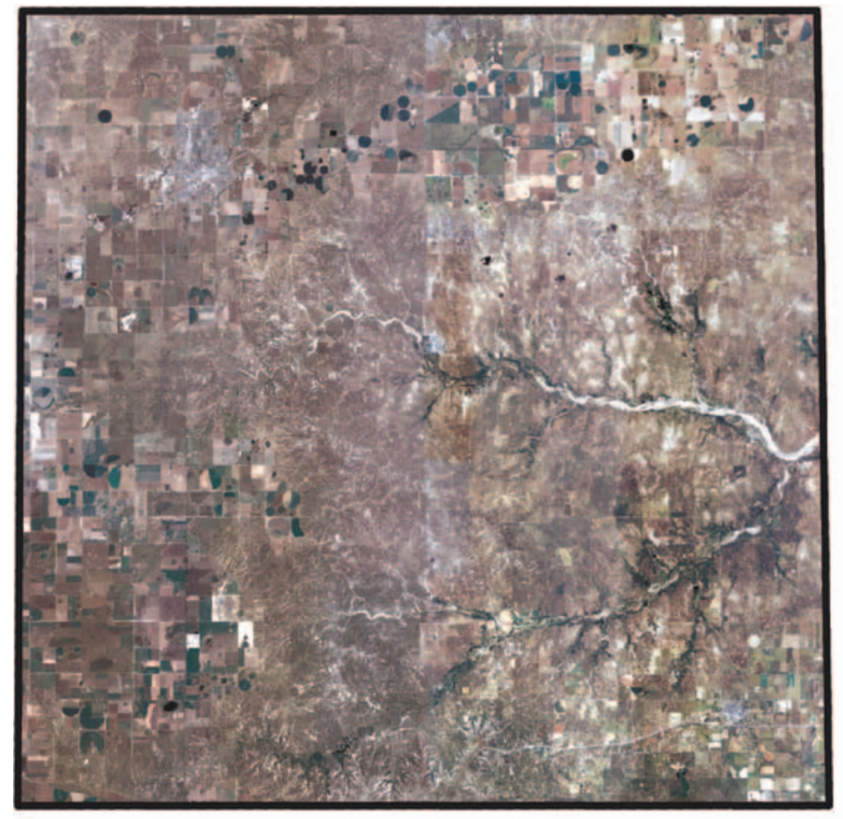

a)

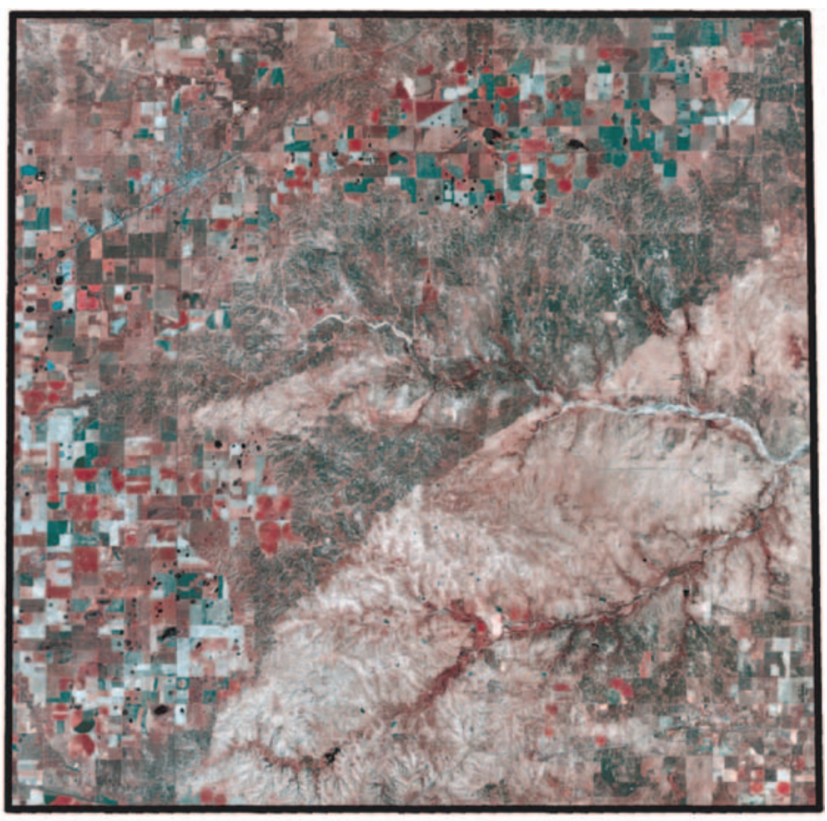

b)

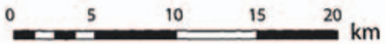

Figure 2. National Agricultural Imagery Program 2-m-resolution mosaic aerial imagery of Gray County, Texas, for a, prefire: acquired July-September 2005 and b, postfire: acquired September 2006.

research, we found that the sensor on the Landsat 7 satellite had a hardware failure on 31 May 2003 that resulted in imagery with significant spatial information gaps. This scanline corrector (SLC) issue continues to affect imagery captured on Landsat 7. The imagery from the 2003 date onward is termed SLC-off imagery. The lack of Landsat 7 quality imagery from 2003 to present is often remedied by 1) using Landsat 5 (active 1984 to present) data, 2) combining Landsat 5 and Landsat 7 images to create "gap-filled imagery," or 3) finding other digital imagery. Unfortunately, after time-intensive searching, we found not one appropriate Landsat 5 image for our study area and time frame. The third option became our primary tactic.

The US Department of Agriculture's (USDA) Natural Resources Conservation Service (NRCS) Data Gatewayii houses fine-resolution National Agricultural Imagery Program (NAIP) mosaic aerial imagery of counties across the nation. A prefire fine-resolution mosaic was available for Gray County with acquisition dates between 28 July and 9 September 2005 (the range of dates coincides with the dates the aerial sensor was flown to capture the entire county). This 2005 image has a spatial resolution of $2 \mathrm{~m}$ and a three-layer spectral resolution of red, green, and blue. The available postfire mosaic was acquired between 18 September

"For more information on the USDA-NRCS Data Gateway, see http:// datagateway.nrcs.usda.gov/GDGOrder.aspx. and 19 September 2006. This image has a spatial resolution of $2 \mathrm{~m}$ and a three-layer spectral resolution of infrared, red, and green (unique to Texas that year). Thus the 2005 prefire image is 7 months before the disturbance (Fig. 2a) and the 2006 postfire image is 6 months after the disturbance (Fig. 2b).

Though finding this imagery felt like a hindrance overcome, the fine-resolution imagery $(2 \mathrm{~m}$ vs. about $30 \mathrm{~m})$ posed its own issues. On this scale, using the images became burdensome (the files were 10 times larger). The second related issue was that accurate classifications were enormously difficult for a county that at 2-m resolution contained somewhere around $900,000,000$ pixels with variations of pixel spectral signatures in the billions. As previously stated, moderate-resolution imagery is appropriate when doing landscape-level reconstructions and this became rather clear.

Processing the imagery. We decided to resample the original $2-\mathrm{m}$ resolution images into $30-\mathrm{m}$ resolution images using ERDAS IMAGINE ${ }^{\circledR}$ raster software (used for all raster processing). This process utilizes bilinear interpolation to average information of surrounding pixels to resample each pixel to a desired resolution while retaining averaged spectral reflectance information. Once both images were coarsened, we created land cover maps using unsupervised classification (allowing the software to group pixels with similar spectral signatures). Each pixel was placed into one of the following categories: developed, sparse to no vegetation, vegetated, or water. We then noted that the fire seemed to have affected exceptionally little or no agricultural or urban areas within 

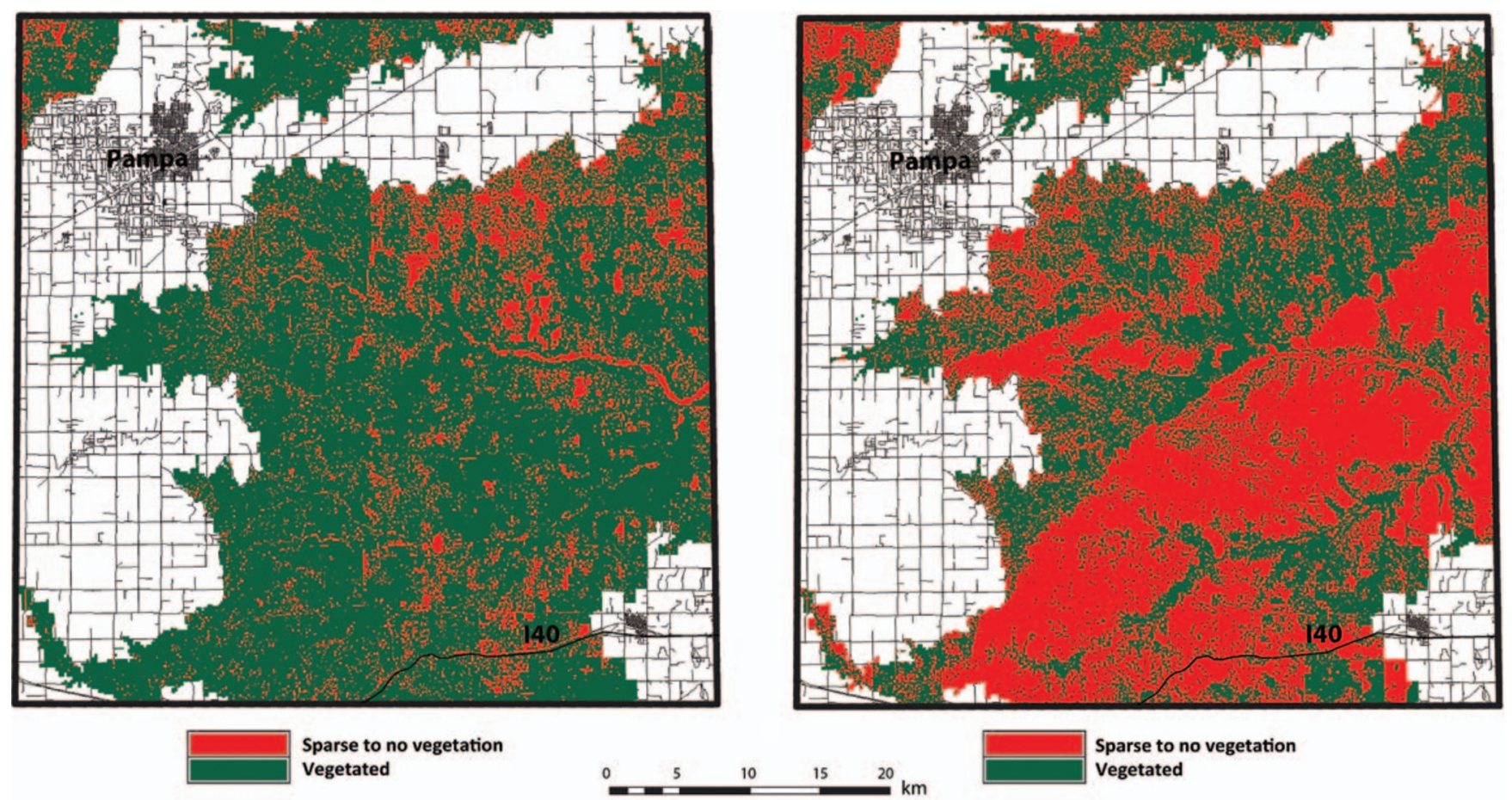

a)

b)

Figure 3. Resampled (from 2-m to 30-m resolution) National Agricultural Imagery Program imagery of Gray County, Texas, with natural rangeland (not agricultural or urban) classified into "sparse to no vegetation" (red) and "vegetated" (green), and roads and county boundary draped for context. a, Prefire map representing landscape in July-September 2005, and b, postfire map representing landscape in September 2006.

the county, and seemed to only affect the natural rangeland areas. Mutch and Keller provide an online map of fire perimeter, ${ }^{2}$ which revealed the same pattern. Another item of note is that the classification process on the postfire image resulted in bare or sparsely vegetated agricultural areas being placed into the bare or sparsely vegetated class created as a result of the fire. This inaccuracy was remedied by slicing each image into two pieces: one being the natural rangeland areas, the other being the agricultural and urban areas. This process was carried out in ESRI ArcGIS ${ }^{\circledR}$ software by creating a delineation polygon around the natural rangeland areas using the original $20062-\mathrm{m}$ image and using the polygon to subset both resampled images into just natural rangeland. The subsetted imagery of just the natural rangeland was returned to IMAGINE and classified into just "sparse to no vegetation" (colored red) and "vegetated" (colored green), as there were no pixels within this area with a distinguished enough spectral signature to be classed as developed or water. When the prefire image classification reached an acceptable $92 \%$ overall accuracy and the postfire image classification reached an acceptable $96 \%$ overall accuracy (this process generates random points across the classified image for comparison to reference data, in this case the original 2 - $\mathrm{m}$-resolution images) the natural rangeland areas were rejoined with the other piece of the imagery, the remainder of the county, for better visualization. The developed and agricultural areas of the county were colored white and county roads and county boundary were colored as black lines. Figure 3a is the prefire resampled, classified NAIP image with natural rangeland classified into "sparse to no vegetation" and "vegetated," with the county boundary and roads for context. Figure $3 \mathrm{~b}$ is the postfire resampled, classified NAIP image with the natural rangeland classified into "sparse to no vegetation" and "vegetated," with the county boundary and roads for context.

IMAGINE generates a table with the number of pixels in each land cover class. We used these data to quantify the amount of land area burned by the fire. We compared the number of pixels of "sparse to no vegetation" prefire to the number of pixels of "sparse to no vegetation" postfire. The difference is quantified as percentage of change and the actual area of change is calculated using the number of changed pixels (for example 10 pixels that became "sparse to no vegetation" would be multiplied by the length and width of each pixel [30 m], which would equal 9,000 $\mathrm{m}^{2}$ ).

\section{Landscape Change}

The "sparse to no vegetation" area within the natural rangeland of Gray County increased by $38.4 \%$ following the East Amarillo Complex wildfires, a large change in the county's land cover. The data shows that 59,143 ha changed to "sparse to no vegetation" between the dates of the 2005 image and 
the 2006 image. This is likely an underestimation of burn area due to the lag time of the postfire imagery. Also of note is the prefire image mosaic, which contained landscape information up to 7 months before the fires; areas with sparse to no vegetation could have burned too. Gray County is 240,351 ha, and the East Amarillo Complex wildfires altered one-fourth of the county (24.6\%). The majority of change occurred in the southeast quadrant of the county where the high plains transition into the Red River breaks and then into the rolling plains. The majority of this area is privately owned and managed rangeland with different management strategies and land use practices (cattle grazing, unused rangeland, agricultural). Because this was such a high-magnitude and fast-moving disturbance, any rangeland that had continuous vegetation on it was affected, whereas agricultural and urbanized areas were mostly unaffected due to a relative lack of fuel for the fire.

\section{In Sum}

The East Amarillo Complex wildfires in Texas in March of 2006 were the largest in the United States since the Yellowstone fires of $1988 .{ }^{1}$ We set upon obtaining remotely sensed pre- and postfire imagery for Gray County, Texas (the only county affected by both fires that make up the complex), classifying the imagery into "sparse to no vegetation" and "vegetated," analyzing and quantifying the area affected, and creating a map of the fire's extent in the county. The hindrances involved in carrying out the analysis are enlightening for land managers and ecologists embarking on burned-area mapping during this particular time frame. The absence of quality moderate-resolution satellite imagery resulted in the use of finer-resolution imagery that required additional manipulation steps for accurate landscape classification. Issues with bare land incorrectly being included in burned area quantification also required methodological revisions. The project required combinations of geographic information systems and remote sensing methods, but ultimately resulted in a burned-area quantification and mapping of the East Amarillo Complex wildfires in Gray County. The purpose of this article is to share our spatial analysis, but also to share the hindrances involved in what originally seemed a basic task. The lessons learned are valuable to anyone wanting to use remotely sensed imagery to map landscapes during this time frame and especially to those particularly interested in this region or landscape-level quantification. Recording of methodology and existence of quality data can result in providing information to other users. ${ }^{9}$ This map and associated information was forwarded to the Texas Agrilife Extension office in Gray County, and is being reviewed for planning and management purposes and posting on their Web site.

\section{References}

1. National Interagency Fire Center. 2011. Historically significant wildland fires. Available at: http://www.nifc.gov/ fireInfo/fireInfo_stats_histSigFires.html. Accessed 21 October 2011.

2. Mutch, R., And P. Keller. 2010. Case study: lives lost-lessons learned, the victims and survivors of the 2005-2006 Texas and Oklahoma wildfires. Available at: http://www.scribd.com/ doc/39355558/Lives-Lost-Lessons-Learned-The-05-06-TXand-OK-Wildfires. Accessed 22 October 2011.

3. Wright, H. A., and A. W. Bailey. 1982. Fire ecology. New York, NY, USA: Wiley. 501 p.

4. Jones, T. A., And S. A. Christopher. 2010. Satellite and radar remote sensing of Southern Plains grass fires: a case study. Journal of Applied Meteorology and Climatology 49:2133-2146.

5. United States Census Bureau. 2010. State and county quickfacts, Gray County, Texas. Available at: http://quickfacts. census.gov/qfd/states/48/48179.html. Accessed 22 October 2011.

6. Авве, D. R. 2011. Gray County. Available at: http:// www.tshaonline.org/handbook/online/articles/hcg08. Accessed 22 October 2011.

7. Cohen, W. B., and S. N. Goward. 2004. Landsat's role in ecological applications of remote sensing. BioScience 54(6): 535-545.

8. Lentile, L. B., Z. A. Holden, A. M. S. Smith, M. J. Falkowski, A. T. Hudak, P. Morgan, S. A. Lewis, P. E. Gessler, and N. C. Benson. 2006. Remote sensing techniques to assess active fire characteristics and post-fire effects. International Journal of Wildland Fire 15:319-345.

9. Chuvieco, E., and E. S. Kasischke. 2007. Remote sensing information for fire management and fire effects assessment. Journal of Geophysical Research 112:G01S90. doi:10.1029/ 2006JG000230

10. Jensen, J. R. 2005. Introductory digital image processing. 3rd ed. Upper Saddle River, NJ, USA: Prentice Hall. 544 p.

See Further Readings online at http://dx.doi.org/10.2111/ RANGELANDS-D-11-00052.s1 for the citations of studies using remotely sensed data and associated technologies in the spatial/environmental analysis of fire and fire risk across a variety of ecotones.

Authors are Research Assistant and PhD Student, Forestry Dept, College of Forest Resources, Mississippi State University, Mississippi State, MS 39762, USA, renaldoarroyo@gmail.com (Arroyo); and Associate Professor, Department of Geosciences, Texas Tech University, Lubbock, TX 79409, USA (Delahunty). 